\title{
Fast Charging Stations: Simulating Entry and Location in a Game of Strategic Interaction
}

\author{
Valeria Bernardo* $\quad$ Joan-Ramon Borrell ${ }^{\dagger} \quad$ Jordi Perdiguero ${ }^{\ddagger}$
}

\begin{abstract}
This paper uses a game of strategic interaction to simulate entry and location of fast charging stations for electric vehicles. It evaluates the equilibria obtained in terms of social welfare and firm spatial differentiation. Using Barcelona mobility survey, demographic data and the street graph we find that only at an electric vehicle penetration rate above $3 \%$ does a dense network of stations appear as the equilibrium outcome of a market with no fiscal transfers. We also find that price competition drives location differentiation measured not only in Euclidean distances but also in consumer travel distances.
\end{abstract}

JEL Classification number: Q52, Q58, L13, L43, R53

Keywords: Electric Vehicle; Fast Charging; Games of Strategic Interaction; Entry Models; Regional Planning

\footnotetext{
${ }^{*}$ Contact author: Institut en Economia Aplicada (IREA) - Grup de Governs i Mercats (GiM), Universitat de Barcelona. Diagonal Av. 690 Tower 6 office 6334, Barcelona 08034, Spain. E-mail: valeriabernardo@ub.edu.

${ }^{\dagger}$ Dep. Politica Economica - Institut en Economia Aplicada (IREA) - Grup de Governs i Mercats (GiM), Universitat de Barcelona; Public-Private Sector Research Center - IESE Business School, University of Navarra, Spain; Centre en Economia de la Salud (CRES) - Universitat Pompeu Fabra. Universitat de Barcelona. Diagonal Av. 690 Tower 6 office 6318, Barcelona 08034, Spain. Email: jrborrell@ub.edu.

${ }^{\ddagger}$ Departament d’Economia Aplicada, Universitat Autonoma de Barcelona; Institut en Economia Aplicada (IREA) - Grup de Governs i Mercats (GiM), Universitat de Barcelona. Edifici B - Campus UAB, Bellaterra 08193, Spain. E-mail: jordi.perdiguero@uab.cat.
} 


\section{A Introduction}

The reduction of carbon dioxide emissions has been one of the main objectives of various United Nations summits with the intention of moderating or reversing climate change. In this regard, the focus has fallen on the road transport sector, which contributes more than any other industry to the volume of emissions. Indeed, according to the latest statistics published by the European Union, the sectors share in total emissions in 2010 was as high as 19.98 per cent.

While electric vehicles are not zero-emissions, given that electricity has to be generated to power them, a number of studies, including (Ahman 2001 and WWF 2008), show that electric vehicles are more efficient, generating lower emissions per kilometer. This reduction is even higher in countries with a mix of electricity generation sources, that is, with a higher share of renewables, whether hydro, wind or solar power.

While the introduction of electric vehicles should play a key role in reducing road transport emissions, their eventual adoption must first overcome a host of barriers. One barrier is the cost associated to electric vehicles (EV) and the willingness to pay from consumers. In this sense, different studies analyze the effect of price over adoption (Larson et al. 2014) and the willingness to pay with or without public subsidies (Helveston et al. 2015 and Parsons et al. 2014) or the effect of public subsidies over EV adoption (Jenn et al. 2013).

Another of the key barriers is the limited number of charging stations that generate 'range anxiety' among users of electric vehicles, fearful of not reaching their destination. In this regard, the deployment of a network of fast charging stations that can reduce this anxiety is essential to the adoption en masse of electric vehicles.

This paper uses a game of strategic interaction to simulate the entry of fast charging stations for electric vehicles ${ }^{1}$. The study evaluates the equilibria in terms of social welfare and firm space differentiation. Demand specification considers consumer mobility. Decisions of consumers and producers are modelled taking into account the expectation of finding a given facility located in each feasible location. The model is applied to the case of the city of Barcelona using the mobility survey, demographic and income data, and the street graph of the city.

To the best of our knowledge, this is the first paper to study the entry and location of fast charging stations using a simulated game of competitive strategic interaction among potential entrants. By so doing, we seek to offer novel perspectives on the following two questions. First, the simulations identify the penetration rate of electric vehicles necessary to have a fast charge station network profitable, and a network that can overcome commuters 'range anxiety'. Second, the model allows us to assess whether competing firms tend to cluster or disperse when consumers move around commuting routes. Differentiation is measured in terms of consumer deviations from the commuting paths to the facilities, rather than distances from a given fixed consumer location to facilities.

With respect to the first question, we calculate that the threshold for the penetration of electric vehicles would have to reach $3 \%$ to guarantee the sustainability of the fast charge station network in Barcelona. This threshold allows commuters to recharge close to $10 \%$ of their energy requirements on the go, and overcome their range anxiety. This threshold

\footnotetext{
${ }^{1}$ We consider like fast charging station the points of $43 \mathrm{kw}$ or more, which can recharge more than $80 \%$ of the battery in less of 30 minutes. The alternative technologies to recharge the car are: accelerated points (between 7 and $22 \mathrm{kw}$ ) that need between 1 and 4 hours; and the conventional points (3kw) that spend 8 hours. We do not consider those alternatives
} 
is 15 times higher than the current penetration rate $^{2}$. With respect to the second issue, we find evidence that price competition drives location differentiation. Price competition lead firms to locate farther away from competitors measured in deviations from commuting paths. This results is novel but similar to the results obtained by the traditional models of space differentiation that measure how firms locate farther apart in distances with respect to consumer fixed locations.

Following on from this introduction, the rest of the paper is organized as follows. In section 2 we present the literature related to this paper on spatial localization of firms. In Section 3, we describe the set-up of the game of strategic interaction used in simulating entry at the different locations. In section 4 we present our data and empirical methodology. Section 5 reports the results obtained in the simulation for the city of Barcelona and the robustness checks, and finally the paper ends by discussing the main conclusions arising from the simulation.

\section{B Literature Review}

There are two forces acting behind firm location decisions known in the economic literature as 'the market power effect' and the 'business stealing effect'. The 'market power effect' is known as the capability of firms to set differentiated prices from competitors when situated farther apart from them. Distance increases the flexibility in the price-setting decision of firms and, therefore, offers incentives to locate far apart from competitors. The 'business stealing effect', on the other hand, offers the opposite incentive. Being close to a competitor increases the probability of stealing some market share. If 'business stealing effect' dominates the 'market power effect', agglomeration of firms is expected.

Previous theoretical studies examining the spatial localization of firms do not report a unique outcome in their predictions as to whether entrants locate in close proximity to incumbents or at some distance from them. Results depend on the assumptions made over consumer preferences and costs, the type of competition examined and the number of competitors in the market. Indeed, a great effort has been devoted in the economic literature to study the spatial competition among firms since the seminal studies of Hotelling (1929) and D'Aspremont and Thisse (1979) that report opposing outcomes of minimum and maximum differentiation, respectively, in a setting with two players. These opposite results are due to the different assumptions regarding consumer transportation cost: while Hotelling (1929) consider lineal transport costs, D'Aspremont and Thisse (1979) introduces transport costs in a quadratic form. Hotelling (1929), however, do not find a unique stable equilibrium when more than two entrants are taken into account. Indeed, closer to our paper are the studies examining competition in both price and location in an oligopoly. In particular, in a setting with heterogeneous consumers Anderson et al. (1992) predict that the agglomeration of firms is the most probable outcome. In this setting, differentiation in pricing implies a differentiation in locations in contrast to uniform price setting that leads towards clustering in locations.

In the empirical literature, clustering outcome tends to dominate; although there is evidence of both outcomes.

Early empirical studies that show clustering include the examination by Borenstein and Netz (1999) and Salvanes et al. (2005) of spatial competition in airline departures times for

\footnotetext{
${ }^{2}$ The current penetration rate in Spain is 0.2\%, according to the International Energy Agency, 2014.
} 
United States and Norway, respectively. The first authors find that when prices are fixed exogenously airlines tend to schedule departure times next to the others or, equivalently, cluster. No competiong in pricing seems to drive clustering in departure times. For the unregulated period, however, results are not conclusive. Salvanes et al. (2005) main finding is that competitors tend to cluster when prices are set endogenously, in the case of duopoly routes compared to monopoly routes. With price competition, oligopolies seem to offer more clustered frequencies rather than monopolies.

Pinske and Slade (1998) and Netz and Taylor (2002) study the case of gasoline retail markets. The first ones focus in studying whether firms with similar contractual agreement tend to cluster or to differentiate. Using only data of the gasoline stations integrated with the four existent oil companies, the authors find that firms with equal contracts tend to cluster. The hypothesis of clustering among firms is obtained also in Vitorino (2012) analysis about shopping centers stores in the United States. Other papers such as Buenstorf and Klepper (2010) and Pennerstorfer and Weiss (2013) also find some sort of clustering.

On the contrary, spacial differentiation is also found in other papers. Of particular relevance for our analysis, the study of Netz and Taylor (2002) reports by focusing in Los Angeles market, that when localized in a more competitive market, gasoline stations tend to spatially differentiated from each other.

Spatial differentiation across firms is also found as a result in Seim (2006) respect to video retail industry and in Borrell and Fernandez-Villadangos (2011) for the case of pharmacies.

Finally, Elizalde (2013) find an inverse relationship between differentiation in multiple dimensions: geographical location and product variety. In the case of the Spanish movie theatre exhibition market, he finds that clustering in location drives differentiation in movie variety, while spatial differentiation in location drives clustering in movie variety. .

Summing up, in the empirical literature, there is evidence of both outcomes, clustering and spatial differentiation depending on the degree and the type of competition in pricing and other dimensions such as location and product quality and variety. So, only by studying the details of the drivers of localization and competition in pricing and in other dimensions that we would be able to foresee whether clustering or sparsity would dominate in the case of the deployment of new networks of fast charging stations for electric vehicles. We will study such details using and entry game of strategic interaction and mobility data.

\section{The entry game of strategic interaction}

Consider a model of entry where within the geographical space there is a road network used by individuals to undertake all types of journey. Consider also that the intersection points of the road network constitute a set of finite feasible locations $j(j=1,2, \ldots, J)$ at which the firms might decide to enter.

Each location is differentiated in terms of two features that are common knowledge to the firms: on the one hand, they are differentiated by the station set-up costs (essentially grid reinforcement and localization costs) outlined in the vector $z_{j}^{r}$, where $r$ indexes different cost shifters $r=1,2, \ldots, R$; and, on the other, they are differentiated in terms of their attraction to consumers, dependent on whether the location provides additional amenities, including, for example, a coffee shop, supermarket, car wash, etc. as detailed in the vector $x_{j}$.

Unlike common entry games and following Houde (2012), we assume that demand is not fixed in any single area and consumers are considered to be mobile between origin and 
destination nodes. We also take into account that consumers differ with respect to income as in Berry et al. (1995)(BLP).

Additionally, as is usual in models of this type, we consider an identically and independently distributed (i.i.d.) random draw constituting profit relevant information on costs across all feasible locations $\left(s_{\epsilon} \epsilon_{j}\right)$ for any feasible location $j(j=1,2, \ldots, J)$, where $s_{\epsilon}$ is the scale of the standard deviation of the fixed cost random draw $\epsilon$. We also consider idiosyncratic consumer tastes regarding the utility for individual $i(i=1,2, I)$ traveling between the origin and destination nodes $\left.o_{i}, d_{i}(\mathrm{o}, \mathrm{d}=1,2, \ldots \mathrm{J})\right)$, where $o_{i} \neq d_{i}$, to purchase from a facility located in $j\left(\varepsilon_{i j}\right)$ to be identically and independently distributed (i.i.d). Both random shocks are private information: the former is private information of the costs for each potential entrant at each location, and the latter is private information for consumer preferences when deciding where to recharge batteries on the go.

Firms take observable information to estimate the expected profits of entering at each feasible location $j$ and simultaneously decide to enter when profits are non-negative. The probability of entry at each feasible location is expressed by $\sigma_{j}$. The sum of probabilities of entry into the market is then given by:

$$
N=\sum_{j=1}^{J} \sigma_{j}
$$

We assume that there is one and only one potential entrant at each node, and that they are one-shop stations. We assume that there are no chains. We have also computed the equilibrium for just one monopolist in the city. Having competing chains is computationally burdensome because of multiple equilibria and the curse of dimensionality. Absence of economies of scale in energy consumption and lack of differentiation between energy supplied by different brands support the non-existence of chains.

It is unclear whether the industry equilibrium would converge towards a structure with most of the stations being independent firms, or just having a few chains of stations. Economies of scale do not appear to be very important as the industry will be able to buy energy from the spot market, and stations are just resellers with some localized grid costs. There might be some economies of scale and scope at the managing procurement and reselling, but there is not room for scale savings.

By contrast, market power would be very important. The industry would be very different whether it converges to the two extremes: fully independent firms or monopoly. We have estimated both extremes. Accordingly, we will show that the number of stations with fully independent firms is a lower bound while in the monopoly case the number of stations would be an upper bound.

We focus on the case of fully independent firms (the lower bound) because it will allow us to discuss whether the industry is offering enough recharging on the go to make the system work even in the case of fully effective market competition among outlets open to the public.

The set up about the information set available for consumers is a key ingredient in the analysis, and it should be conveniently modelled taking into account that our aim is to analyze the entry decisions by potential station entrepreneur. What it is important is to model accurately the expected sales of any potential entrant at each location (equation 9 bellow).

From the point of view of each potential entrant, the more accurate way to form the expectation of sales is looking at the expected number of consumers that will stop by the 
station. This expectation is modelled from the consumer perspective using equations $2,5,7$ and 8 bellow.

Consumers compare utility across all potential locations of recharging stations, and also compare them to the utility from recharging at home. So, we assume that for each location $\mathrm{j}$, consumers have a correct expectation of pricing and amenities at that location, and the deviation from their path.

What we then assume is that, consumers will opt for that station if that is the option that delivers the maximum utility from the close set of exhaustive and mutually exclusive discrete choice options: whether each station provides the maximum utility compared to recharging at home or recharging on the go in any other potential location.

We assume as in Bajari and Nekipelov (2010) that potential consumers of each station compare recharging at $\mathrm{j}$ with the alternative stations weighed by a vector of expectations of finding any station available in any potential location $\sigma_{k}$ for any $k=1,2, k J$ but $k \neq j$. OJO REVISAR LATEX

So doing, each entrant expected sales depend on whether, in equilibrium, whether there are other competitors opening an station in the nearby.

For searching the equilibrium, we start setting this vector all equal to ones, as if consumers could recharge in any location (all potential stations open to the public). And also, we look for the case in which this vector all equal to zeros, as if consumers could recharge only in that particular location or at home. We compute all equilibra iterating from this vector of probabilities of entry that soon converge to probabilities very close to one or zero for a reduced set of locations.

\section{C.1 Demand specification}

Let demand for the fast charging of electric vehicles be modeled as a discrete choice problem over $j=0,1,2,3, \ldots, J$ possibilities. Consumers are therefore able to choose between consuming at one of the $J$ feasible locations or recharging at home (outside-good, $j=0$ ).

Let the commuting paths of individuals between origin-destination zones be called $(o, d)$

Additionally, let the utility of buying from store $j=1,2, \ldots, J$ depend on the distance between the commuting paths of the individuals and location $j$, the features of the location, the characteristics of individuals and unobservable idiosyncratic tastes over each $j$ location.

Then, the deterministic component of the indirect utility of recharging from station $j$ to individual $i$ that makes a trip between $o, d,\left(\phi_{i j}\right)$ can be expressed as follows:

$$
\phi_{i j}=-\lambda D\left[\left(o_{i}, d_{i}\right), l_{j}\right]+\beta x_{j}-\left(\bar{\alpha}-\alpha \log Y_{i}\right) p_{j}
$$

being the indirect utility function of recharging at any of the feasible locations $j$ :

$$
u_{i j}=\phi_{i j}+\varepsilon_{i j}
$$

and the indirect utility function of recharging at home:

$$
u_{i 0}=0+\varepsilon_{i 0}
$$

where $D\left[\left(o_{i}, d_{i}\right), l_{j}\right]$ represents the distance between path $\left(o_{i}, d_{i}\right)$ and facility $j$ with its location expressed as $l_{j}$ and $\lambda$ is a parameter that expresses the disutility of deviating from the commuting path to reach facility $j$ measured in minutes; $x_{j}$ is a binary variable that takes the value of 1 whenever there are any amenities, such as car wash services, supermarkets or 
coffee stores, at feasible location $j ; \bar{\alpha} p_{j}$ measures the disutility of paying the posted prices; and $\alpha \log \left(Y_{i}\right) p_{j}$ introduce the interaction between income and prices and express the differentiation between individuals that make the same trip in terms of price sensitivity for different levels of personal income.

As usual in multinomial logit models, the utility of recharging at home is normalized to zero.

Consumers derive utility from not deviating from their commuting path (equation 2). So the longer the commuting path, the better off are the consumers once there is another station available, and the more likely they are of recharging at that additional charging stations. Thus, the probability that individual $i$ making trip $o, d$ will recharge at facility $j, \Phi_{i j}$ is given by a multinomial logit model, where the individual is allowed to choose between recharging at any facility $j=1,2, \ldots, J$, recharging at home $j=0$, or buying from any other location. However, as we focus in a utility model in which each consumer and potential entrant does not know where all the available stations are, following Bajari and Nekipelov (2010) and Borrell and Casso (2011) we allow consumers to evaluate the utility of recharging at each node with respect to the utility of recharging at any other node in expectation of the probability that finally a station will be available at these other nodes. This is why the existence of a facility at any other location apart from $j$ enters in expected terms as the probability that individual $i$ making trip $l$ will find a facility at any other location. This probability of having any entrant at each location is named by the parameter $\sigma_{k}$. Consumers form their expectation of $\sigma_{k}$ simultaneously, as an assumption of tractability.

Thus, the probability that individual $i$ making trip $o, d$ will recharge at facility $j, \Phi_{i j}$ is given by a multinomial logit model, where the individual is allowed to choose between recharging at any facility $j=1,2, \ldots, J$, recharging at home $j=0$, or buying from any other location. However, as we focus in a utility model in which each consumer and potential entrant does not know where all the available stations are, following Bajari and Nekipelov (2010) and Borrell and Casso (2011) we allow consumers to evaluate the utility of recharging at each node with respect to the utility of recharging at any other node in expectation of the probability that finally a station will be available at these other nodes. This is why the existence of a facility at any other location apart from $j$ enters in expected terms as the probability that individual $i$ making trip $l$ will find a facility at any other location. This probability of having any entrant at each location is named by the parameter $\sigma_{k}$. Consumers form their expectation of $\sigma_{k}$ simultaneously, as an assumption of tractability.

$\Phi_{i j}$ is therefore given by:

$$
\Phi_{i j}=\frac{\exp \left[\phi_{i j}\right]}{1+\exp \left[\phi_{i j}\right]+\sum_{k=1, k \neq j}^{J} \sigma_{k} \exp \left[\phi_{i j}\right]}
$$

and the probability for the outside good is given by:

$$
\Phi_{i 0 l}=\frac{1}{1+\sum_{j=1}^{J} \sigma_{k} \exp \left[\phi_{i j l}\right]}
$$

This demand specification clearly predicts, as expected, that recharging on-the-go increases with the number of charging stations open to the public. And, on the contrary, recharging at home decreases with the number of charging stations available.

On the other hand, we assume that individuals demand heterogeneous quantities of energy proportional to the distance traveled per year, which is obtained by multiplying all the trips 
between origin $\left(o_{i}\right)$ and destination nodes $\left(d_{i}\right)$ as registered in the survey for each individual $i$ by the number of days in a week and the number of weeks in a year.

We also consider that the quantity of energy demanded depends on the share of the electric vehicle $(v)$. It also depends on the share of consumption of the electric vehicle recharged on the go $(\tau)$, and the energy consumption per kilometer $\left(C_{0}\right)$. We assume that all these parameters are common for all individuals. Therefore, individual demand for energy on the go $\left(e_{i}\right)$ is given by:

$$
e_{i}=v \tau C_{0} D\left(o_{i}, d_{i}\right)
$$

\section{C.2 The supply}

Given the previous set-up, expected sales at location $j\left(q_{j}\right)$ are given by integrating, by simulation, the probability of recharging at each location $j$ across consumers:

$$
q_{j}=\sum_{i=1}^{I} p_{j} \Phi_{i j} e_{i}
$$

and expect profits are therefore as follows:

$$
\pi_{j}=q_{j}-\sum_{i=1}^{I} c_{j} \Phi_{i j} e_{i}-F_{j}
$$

where $\sum_{i=1}^{I} c_{j} \Phi_{i j} e_{i}$ are the variable costs of providing energy common to all locations, and $F_{j}$ is the fixed costs associated with location $j$.

Entrants' profits (equation 9) depend strongly on how close competitors are located trough market shares, and pricing (equation 5, 8 and 11 below). Market shares and pricing decrease with new entrants. So, there is a business stealing effect modeled in the game.

Let the fixed costs $F_{j}$ have an observable part comprising a common component in equipment for all locations $f$, a component that is specific to each location $j$ as regards grid reinforcement and localization $z_{j}^{r}$, and the unobservable (i.i.d.) random draw on costs $\left(s_{\epsilon} \epsilon_{j}\right)$. Therefore, the fixed cost equation is given by:

$$
F_{j}=f+\sum_{r=1}^{R} \mu_{j}^{r} z_{j}^{r}+s_{\epsilon} \epsilon_{j}
$$

where $\mu_{j}^{r}$ is a parameter that takes different values according to variable $z_{j}^{r}$, for any $r=1,2, \ldots, R$ and $s_{\epsilon}$ is the scale parameter of the variance of the random draw of the fixed cost at each location. Increasing the standard deviation we would make costs more location specific according to unobservable factors, while decreasing it, we would be making fixed costs more closely related to the observable deterministic part of fixed costs (grid reinforcement costs and rental costs). In the simulations, we are assuming that the deterministic part of the fixed costs is prevalent in our case of study and that the scale is equal to one: $s_{\epsilon}=1$.

\section{C.3 Solving the entry game of strategic interaction}

We assume that each entrant competes à la Bertrand in prices with respect to the set of expected entrants that are differentiated by location. From the system of first order conditions, the Nash equilibrium pricing is as follows: 


$$
p_{j}=c_{j}-\frac{\sum_{i=1}^{I} \Phi_{i j} q_{i}}{\sum_{i=1}^{I} \frac{\partial \Phi_{i j}}{\partial p_{j}} q_{i}}
$$

where $\frac{\sum_{i=1}^{I} \Phi_{i j} q_{i}}{\sum_{i=1}^{I} \frac{\partial \Phi_{i j}}{\partial p_{j}} q_{i}}$ is the mark up of the firm that enters at location $j$.

Consider now that from Bertrand competition an equilibrium price is obtained. Finally, suppose that given equilibrium pricing $p_{j}$ and expected profits at each feasible location $\pi_{j}$, each potential firm at each node simultaneously decides whether to enter or not to enter. As we assume that the unobserved costs distribute as a type-one extreme value random shock, the probability of entry is given by the following logit model:

$$
\sigma_{j}=\frac{\exp \left[E\left(\pi_{j}\right)\right]}{1+\exp \left[E\left(\pi_{j}\right)\right]}
$$

It is straightforward to verify that the result of the game of strategic interaction gives the total number of entrants to the market $N$ :

$$
N=\sum_{j=1}^{J} \sigma_{j}
$$

As far as the equilibrium is concerned, the type-one extreme value distribution of the error term guarantees that the firms conjectures are monotonic, continuous and strictly bounded inside the set $(0,1)$. Therefore, by Brower's fixed point theorem the entry game of strategic interaction has at least one solution.

\section{Data and methodology}

We use Barcelona as a case study for testing how the free entry game of strategic interaction simulates the entry and location of fast charging stations in a dense city (for which we have access to mobility survey data as well as demographic and income data), under a number of assumptions regarding the values of certain parameters, including the percentage of electric vehicles in the citys overall vehicle park.

The origin-destination paths. The origin-destination commuting paths were built using four sources of information: the Mobility Survey conducted by the Metropolitan Transport Authority and the Territorial Department for the year 2006; the Catalonia Road Graph; and, the Barcelona Neighborhood and Census Zoning Maps published by the Regional Government.

The survey collects data on all the trips made by the residents of Catalonia of above 4 years old. Participants in the survey are randomly selected and the interview is made by phone. Within the survey, the Metropolitan Region of Barcelona is divided into 308 zones, 63 of which correspond to the city of Barcelona. The data corresponding to the trips made by residents of the Metropolitan Region in their private vehicles within the Metropolitan Region number 58,443. Of these, 18,411 have Barcelona as their origin or destination while 6,330 are made within the city. Taking into account commuter trips, the most frequent origindestination zone is 17 (the southern entrance to the city), while in the case of trips within the city the mode zone is 12 , in the city center. 
The Catalonia Road Graph was filtered leaving information just for the city, and four nodes and two arcs were added using the city map published online at the website of the Barcelona City Council. In total, the road graph contains 891 nodes and 2,436 arcs. These arcs were made bidirectional, as the map uses a simplified version of the city network.

The Barcelona Neighborhood Map used corresponds to 2011 and it divides the city in 75 neighborhoods. It provides population information disaggregated by gender and area in square meters for each of the polygons. The total population is $1,631,259$ inhabitants, distributed through the neighbourhoods. The smallest neighbourhood in terms of population has 466 people and the largest one 58204 .

The Census Zoning map used also corresponds to 2011. It divides the city in 1,063 census zones and provides the same information as the former map but for smaller statistical areas. The mean population per zone is 1,537 , while the minimum and maximum populations in a zone are 466 and 7,291 , respectively.

In order to estimate the shortest path corresponding to every commuting trip, an origindestination (OD) matrix was built. For trips within the city, a three-step methodology was used. First, each origin and destination zone was assigned to a node in the network by first building the geometric centroids and then assigning them to the corresponding node with the population density criterion. This yielded as a result, original $(b)$ origins and destinations $o^{b}$ $d^{b}$, with $b=1,2, \ldots, 63$. Second, the spatial correlation within the origins and destinations was tested and kriging techniques were applied. With the results of the kriging and the density of population corresponding to each node, we were able to assign a probability of being an origin or a destination to all the nodes in the network. Therefore, in our case study, final origins and destinations are given by: $o=1,2, \ldots, 891$ and $d=1,2, \ldots, 891$. Finally, a random sample with uniform distribution was built for every origin and every destination of the paths in order to assign the nodes corresponding to each commuting path within the survey (see Appendix A for a fuller explanation).

Commuters were assigned to the corresponding node of entry in to or out of the city, according to the shortest path given by googlemaps. The destination or origin within the city was assigned as above.

To estimate the commuting path between each origin and destination, Dijkstras shortest path algorithm was used (Dijkstra $1959^{3}$ ). Thus, we ascertained the mobility flows via the 891 nodes and 2552 arcs across the city of Barcelona.

With this information, we were able to make a plausible approximation of the mobility flows in the city for all types of movement: home to work, home to study, home to shopping, home to any other destination, all back-to-home movements, and paired movements between all these destinations across the 891 nodes and 2436 arcs.

We are using a graph with the main roads as arcs and the main nodes as spots as origins or destinations of their commuting paths, and also available as locations for charging stations in the city. So the algorithm is good at comparing all the paths from any node $\mathrm{A}$ and $\mathrm{B}$, and computing the shortest distance from that two spots. The model is also good at computing the shortest deviation for any consumer going from A to B for recharging at C. However, we are assuming that there is not congestion within the graph, as if all the main roads would be able to attract traffic. This is not probably the case in some rush hours.

So, there might be some differences to real traffic flows due to some rush hours localized congestion; however mean differences for all year round shouldn't be too large if the main

\footnotetext{
${ }^{3}$ This algorithm connects any two nodes from a network through the shortest path between them
} 
roads suffer the same mean level of congestion or capacity constraints across the city at the same time hours. In any case, congestion is not controlled for in our exercise as we do not have real time data, we are offering a mean year round approximation that it is not biasing our results of localization in the city as long as unobservables related to congestion are i.d.d across city arcs and nodes.

The feasible locations. The nodes were differentiated in terms of set-up costs and their ability to attract demand. To this end, a map showing all fuel stations, hypermarkets and malls in the city was drawn up and these facilities were assigned to the closest node in the network. Second, the nodes in the network were assigned to one of the 73 neighborhoods of Barcelona.

The set-up cost vector $z_{j}^{r}$ contains four different variables (i.e. $\mathrm{R}=4$ ). For the grid reinforcement cost $(\mathrm{r}=1,2,3)$, locations were aggregated into three categories according to the following criteria (Figure 1): nodes with a petrol station and a car wash $\left(z_{j}^{1}=1\right)$; nodes with a petrol station with more than $10 \operatorname{pumps}\left(z_{j}^{2}=2\right)$; and neither of the previous two options $\left(z_{j}^{3}=3\right)$. Entrants at most of the nodes need to pay set-up costs upfront and in full for grid reinforcement as nodes are equipped with neither a petrol station with a car wash nor a petrol station with ten $\operatorname{pumps}\left(z_{j}^{3}=3\right)$. Entrants at nodes with a petrol station with more than ten pumps has to afford half of the grid reinforcement cost $\left(z_{j}^{2}=2\right)$. Finally, at locations with a car wash entrants do not have a grid reinforcement cost $\left(z_{j}^{1}=1\right)$. However, all facilities must pay the localization cost corresponding to the rent of a commercial establishment in the neighborhood in which the node is located. Following, $z_{j}^{4}$, where it takes 73 different values according to the localization in the corresponding neighborhood. Set-up costs range from $1,236 €$ to $57,676 €$.

Petrol station data were obtained from the website of the Spanish Ministry of Industry, Tourism and Commerce. The costs of connection were taken from Schroeder and Traber (2012) and set in 15,000 €. Costs of localization in Barcelona were assigned according to the average price in 2007 of a square meter of a commercial establishment as published by Barcelona Open Data.

The malls and hypermarkets (Figure 1) together with the amenities of the petrol stations were used to characterize the feasible locations in terms of their ability to attract demand. This feature was included by using a binary variable that took a value 1 whenever amenities such as a bar, restaurant, store, and so on were available at the feasible location. 


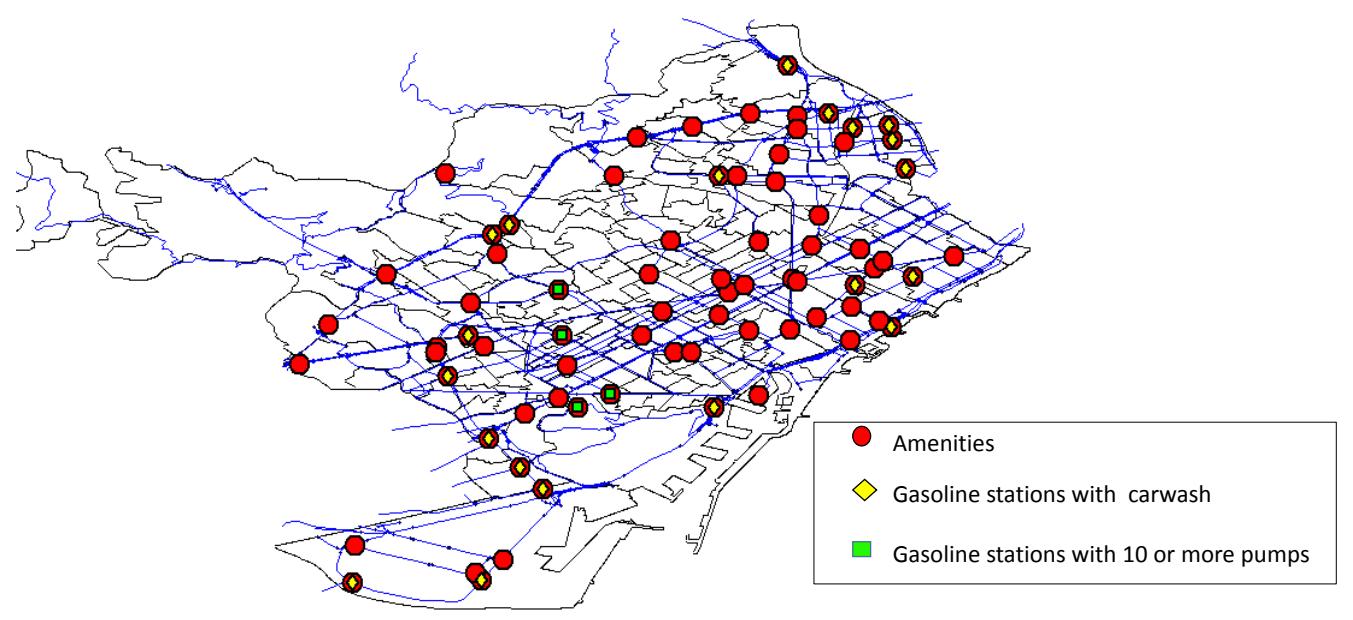

Figure 1: Locations with amenities, gasoline stations with carwash and gasoline stations with 10 or more pumps

The marginal cost of providing energy was considered to be equal to 0.15 euros $/ \mathrm{kWh}$ applied to a standard recharging of $16 \mathrm{kWh}$ for every feasible location. This represents the average cost of the kWh plus the transport cost for the Spanish market in 2013.

Assumptions regarding consumers and mobility. Consumers considered were all making trips in private vehicles between the different zones of the city and commuting trips to Barcelona from the rest of Catalonia.

An homogeneous penetration of electric vehicles in each zone of Barcelona was considered. Income data for the citys residents were taken from a report on income distribution conducted by the Barcelona City Council and the Catalan Statistics Institute (IDESCAT). Income data for commuters resident in the Metropolitan Region were taken from the statistics prepared by the Barcelona Provincial Council. And data for the residents of the rest of Catalonia were taken from IDESCAT. The average income for the individuals in the sample takes a value of $16,439.41$ e/year, with a standard deviation of 5,600.26 e/year, where the maximum income was 33,809 e/year and the minimum 10,276 e/year.

The parameters The equilibrium of the entry game of strategic interaction was solved given the parameters of the indirect utility function: $\{\lambda, \beta, \bar{\alpha}, \alpha\} ; v$ and $\tau$ for the quantity of energy needed; and, $\mu_{j}$ for the grid reinforcement costs.

Of these, $\lambda$ was taken from Houde (2012) (1.0004), as it is the only paper that includes the disutility of deviating from the commuting path in the estimation of gasoline demand when considering consumer mobility.

$\beta$ was set-up at 2.5 , as the existence of amenities constitutes a fundamental characteristic at the moment of choosing whether to recharge at a station or to recharge at home, taking into account that the average time for a recharge is 20 minutes.

Regarding price elasticity, $\bar{\alpha}$ was set-up at 0.65 and $\alpha$ at 0.06 . 
Robustness checks for the indirect utility function parameters were made and are shown in the Results Section.

Different scenarios were considered with regard to the share of electric vehicles (EVs) within the overall vehicle park $v$. Our results are presented for the $1 \%, 3 \%$ and $5 \%$ scenarios. The last scenario was included as this is the goal for EV penetration set by the European Commission, while the first two are included to ensure that the market at least meets the $10 \%$ recharging on-the-go target.

To fix the upper bound of the market potential, the share of consumption of the electric vehicle recharged on the go, $\tau$ was considered to be equal to $10.5 \%$. This choice was conditioned by the calibration of the model to approximate the recharging on the go to the $10 \%$ projections made by the European Commission.

Finally, $\mu_{j}^{1}$ takes the value of 0 whenever there is a petrol station with car wash facilities at the feasible location, $\mu_{j}^{2} 1,019 €$ a year whenever there is a petrol station with 10 or more pumps at the location, $\mu_{j}^{3} 2,038 €$ a year when the location does not have any of the aforementioned facilities. These results are derived from considering an annual payment with an interest rate of 6 per cent for a ten-year credit for grid reinforcement costs. Finally, $\mu_{j}$ takes the value of 1 for $r=4$.

Methodology. To avoid the curse of dimensionality, we integrate logit demand across a random sample of only 100 representative individuals a la BLP. They were selected from the Mobility Survey as a random sample but respecting the weights of each trip (See Appendix B for details).

The probability of entering at each location was obtained via a simulation process including the simultaneous determination of: i) the probability of individual $i$ on origin-destination trip $i$ recharging at facility $j\left(\Phi_{i j}\right)$; ii) the Bertrand (Nash in prices) equilibrium pricing at each feasible location $j\left(p_{j}\right)$; and, iii) the probability of entry at location $j\left(\sigma_{j}\right)$.

The probability of individual $i$ on origin-destination trip $i$ refueling at facility $j\left(\Phi_{i j}\right)$ was introduced as a multinomial logit with random coefficients as in Berry et al. (1995). The sources of heterogeneity included are two: i) origin-destination path $\left(o_{i}, d_{i}\right)$; and ii) income $Y_{i}$.

The price equation $p_{j}$ was derived from the first order condition of the firms by considering Bertrand competition (Nash in prices equilibrium). See also Berry et al. (1995). Finally, the probability of entry at location $j\left(\sigma_{j}\right)$ was introduced as a discrete choice logit model where, following Borrell and Casso (2011), the expected profits of a potential entrant at each location $j$ depend on the probability of having any number of competitors at the other $j-1$ feasible locations.

The simultaneous non-linear entry game problem was solved in Matlab by iteration.

To search for multiple equilibria, first, we obtained the vector of entry probabilities in equilibrium starting iterations with $\sigma_{1}=\ldots=\sigma_{k}=\ldots=\sigma_{J}=1$ as if consumers expect to find a fast charging station at all nodes and entrants expect to have a competitor at all other nodes, and the vector of entry probabilities in equilibrium starting iterations with $\sigma_{1}=\ldots=\sigma_{k}=\ldots=\sigma_{J}=0$ as if consumers expect to find only one fast charging station and entrants at each node expect to be monopolists and to have no competition at the other nodes. Second, we run the entry game from both extreme solutions to look for the equilibria, allowing the model to converge to multiple equilibria.

The number of stations at the first iteration assuming that entrants disregard the entry of 
other firms in other locations is far from the number and location of stations we obtain from the full game of strategic interaction. In the case of the $5 \%$ penetration rate, disregarding the interaction would drive more than 300 stations in the market, while the final equilibrium with non-negative profits and full strategic interactions the number of stations goes down to only 83 as we will show bellow.

\section{E Results}

\section{E.1 The equilibria}

The model shows that a unique stable equilibrium can be achieved for every level of penetration of electric vehicles (EVs) considered. Starting iterations with $\sigma_{1}=\ldots=\sigma_{k}=\ldots=\sigma_{J}=1$ as if consumers expect to find a fast charging station at all nodes and entrants expect to have a competitor at all other nodes always renders a unique equilibrium with the expected number of entrants being equal to only 2, 51 entrants or as many as 83, depending on the level of penetration of EVs being $1 \%, 3 \%$ or $5 \%$ respectively. Starting the iterations by assuming that $\sigma_{1}=\ldots=\sigma_{k}=\ldots=\sigma_{J}=0$ as if consumers expect to find only one fast charging station while the entrants at each node expect to be monopolists, we always obtain these same equilibria as previously described (Figure 2).

In the equilibria, we obtain very sharp estimated $\sigma_{j}$ as those are taking values very close to 1 (0.999) or very close to 0 (0.001). This means that exact location of the stations at each equilibria is very sharp and clearly identified. Nodes are offering clearly non-negative profits for the place where stations enter, while clearly negative profits for all the rest. 
1\% Share Electric Vehicle

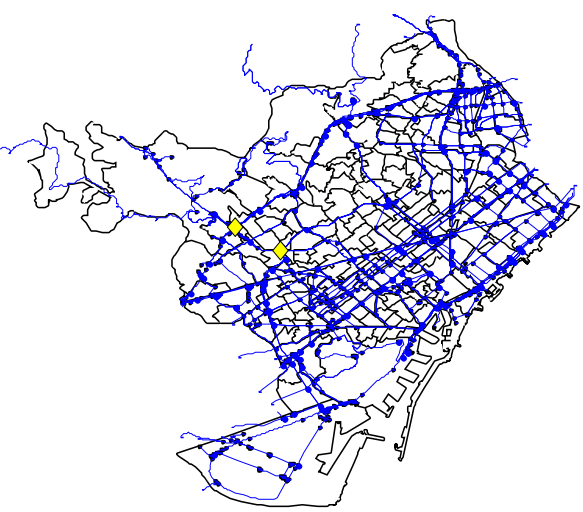

3\% Share Electric Vehicle

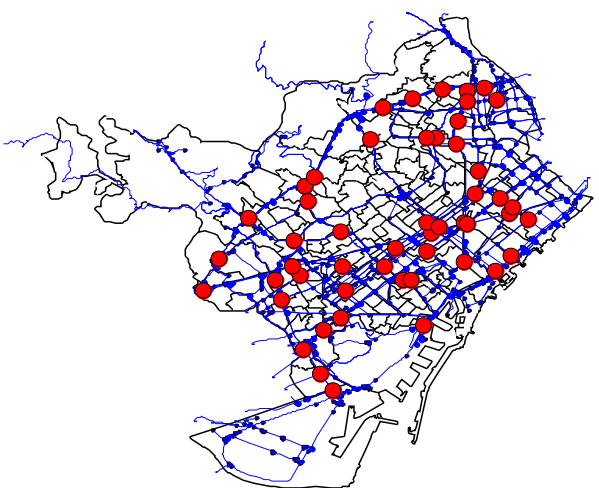

5\% Share Electric Vehicle

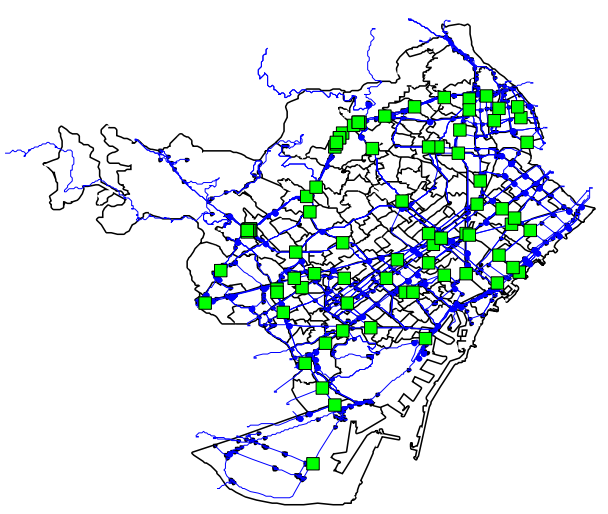

Figure 2: Equilibria at 1\%,3\% and $5 \%$ share of $\mathrm{EV}$

The entry game of strategic interaction shows that the free market solution offers sufficient recharge on the go from a 3\% threshold of EV penetration. Even though an equilibrium is achieved for a $1 \%$ share of EV penetration, recharging on the go would satisfy only an insignificant part of energy needs $(0.482 \%)$ (Tablei). In the case of $3 \%$, the market can be considered to offer sufficient recharging on the go, since $8 \%$ of energy needs would be met by recharging in the network of fast charging stations. Finally, if $5 \%$ of the vehicle park were to be electric, around $9.5 \%$ of recharges would be on the go, which is very close to the $10 \%$ target set by the European Commission (MEMO 24/12/2013 EC). Note that Table i shows, as expected, that the mean price falls with the number of entrants. Congestion problems do not appear to be relevant, as all the entrants show available capacity after serving demand in any equilibria: none station has ever to attend near or more than 96 recharges per day (24 hour availability times 2 recharges per hour times 2 plugs per station).

Table i: Equilibria at 1\%, $3 \%$ and $5 \%$ of penetration of EV

\begin{tabular}{|l|r|r|r|}
\hline Variable/ Share EV & $\mathbf{1 \%}$ & $\mathbf{3 \%}$ & $\mathbf{5 \%}$ \\
\hline Number of entrants & 2 & 51 & 83 \\
\hline Share 'on the go' (\%) & 0.482 & 8.06 & 9.47 \\
\hline Mean Price $(€)$ & 25.09 & 18.87 & 18.55 \\
\hline
\end{tabular}


Expected profits seem to depend more on demand drivers as distance to stations and existence of amenities. Nevertheless, the entry cost play also a role in determining the entry locations. In table below it is shown a full characterization of the locations of the fast charging stations for each rate of penetration of EV.

Table ii: Characterization of locations at $1 \%, 3 \%$ and $5 \%$ of penetration of EV

\begin{tabular}{|l|r|r|r|r|}
\hline Variable/ Share EV & $\mathbf{1 \%}$ & $\mathbf{3 \%}$ & $\mathbf{5 \%}$ & Total feasible locations \\
\hline Number of locations & 2 & 51 & 83 & 891 \\
\hline Amenities & $100 \%$ & $100 \%$ & $75 \%$ & $8.4 \%(75)$ \\
\hline Grid reinforcement costs & & & & \\
Type 1 (0 cost) & $0 \%$ & $23.5 \%$ & $19 \%$ & $2.24 \%(20)$ \\
Type 2 (half cost) & $0 \%$ & $4 \%$ & $4 \%$ & $0.45 \%(4)$ \\
Type 3 (full cost) & $100 \%$ & $72.5 \%$ & $77 \%$ & $97.3 \%(867)$ \\
\hline Localization costs (average $€$ ) & 2250 & 1786 & 1791 & 1811 \\
\hline
\end{tabular}

\section{E.2 The spatial competition}

In addition, we find evidence that supports the spatial differentiation of competitors in the free-pricing competitive scenario. Results are robust with two different counterfactuals and several distance measures.

We first compared the competitive outcome to that obtained by simulating a monopoly with free entry. As state in Netz and Taylor (2002), the monopoly equilibrium should be characterize by a situation where facilities are located minimizing transportation costs of consumers. These locations maximize the amount of consumer surplus that can be appropriated by the monopoly by charging higher prices. Introducing competition, if firms have a tendency to a minimum differentiation the outcome would be clustering among competitors. By contrast, if competitive firms tend to maximum differentiate, increasing competition would turn in firm spatial differentiation. Hence, whether competition increase the degree of spatial differentiation or not relies on whether firms tend to maximum or minimum differentiate.

Differently from the airline industry (See Salvanes et al. 2005) and equal to gasoline stations, we expected to find higher spatial differentiation among firms as the degree of competition in the market increases. Overall, because possible capacity contraints may encourage firms to locate far from competitors and charge higher prices than trying to steal some sales by locating close.

We calculated the monopoly solution by obtaining the system of price equations from the first order condition of the profit maximization problem, as usual in these kinds of games. Hence, price for the $j$ location is given by:

$$
p_{j}=c_{j}+\Delta^{-1} \sum_{i=1}^{I} \Phi_{i j} q_{i}
$$

where $\Delta$ is a $J$ by $J$ matrix, whose $(j, k)$ element are given by:

$$
\Delta_{j, k}=\frac{-\partial\left(\sum_{i=1}^{I} \Phi_{i k} q_{i}\right)}{\partial p_{j}}
$$

and the $(j, j)$ elements are given by the facility $j$ own price elasticity: 


$$
\Delta_{j, j}=\frac{-\partial\left(\sum_{i=1}^{I} \Phi_{i j} q_{i}\right)}{\partial p_{j}}
$$

We compare the results in terms of location:where would the monopolist locate the same exact number of entrants than in the single facility competition case.

The second benchmark is the counterfactual given by establishing a uniform regulated price. With no entry restrictions and the same number of entrants, the comparison with the uniform regulated price scenario allow us to identify differences in location due to price competition. Here again, we expected to find larger location differentiation between firms in the free-pricing and single firm competition setting.

Recall that, differently from previous literature, in our case, transportation costs are given by the distance traveled by consumers to facilities as deviations from their commuting path. Consumers are not expected to stop by a facility close to their home but close to their commuting path. Hence, we first measure differentiation between firms through the average distance consumers need to deviate from their commuting path in the different settings. If the deviation is lower, then firms must be located closer to the paths were demand flows and to each other (being the extreme case the monopoly setting). If the average deviation is higher, firms must be located far away from competitors increasing the distance commuters have to travel to reach them. To check the robustness of results, in second place we use two different measures of geographical distance: a) we compare the Euclidean distance between competitors in the different settings with different definitions of market size (half-, one-, and two-mile radii) as in Netz and Taylor (2002); b) we compare the distance between competitors taking into account network paths in the graph.

For the uniform price benchmark, for the $3 \%$ scenario, the regulated price was set at $16 €_{\text {so }}$ as to achieve the same outcome as in the free pricing case in terms of the number of entrants (51 facilities). For the $5 \%$ scenario, the same procedure was adopted and the regulated price was set at $26 €$ reaching 83 entrants as in the case of free entry.

Results measuring the distance trough deviations of commuting paths are presented for the $5 \%$ of electric vehicles scenario. For the $3 \%$ scenario results are inconclusive: the monopoly setting do not render to a unique stable comparable equilibrium, and, statistical significance of the results obtained in the second benchmark can not be guaranteed. This is, the difference in average deviation is only statistically significant in the $5 \%$ scenario.

The results for the three settings are presented in (Tableiii).

Spatial differentiation of firms when both price and entrance are unregulated is the outcome we obtain when single facility firms compete. The monopoly case renders the largest degree of facilities agglomeration around communting flows, and therefore, to each other facility. As shown in the table, the average deviation of the commuting path in the monopoly case is just 9 meters. We also observe that, as expected, the deviation and distance between facilities significantly increases if single facility firms compete in the market.

We restrict the analysis to the location of the more profitable 83 facilities in the monopoly case (5\% penetration rate), the same number as in the single facility firms competition. However, in monopoly, the number of facilities with non-negative profits is much larger (361) as mean pricing is also much higher. These more profitable locations in the monopoly case are the locations in which travel costs of commuters are minimized given the number of locations are 83.

The comparison between the free-price setting and uniform price-setting also shows that 
deviation is larger when firms are allowed to compete in prices. This was the expected result as in the regulated setting the market power effect is not biding and therefore firms have only incentives to locate closer to competitors to steal part of their sales. However, the small difference found between the uniform and free price settings also may show that the market power effect is important but not very large.

Table iii: Distance between competitors measured in deviations of the consumers

\begin{tabular}{|l|r|r|r|}
\hline Share EV- Entrants & \multicolumn{3}{|c|}{$\mathbf{5 \% - 8 3}$} \\
\hline Variable & Free & Regulated & Monopoly \\
\hline Average deviation $(\mathrm{m})$ & $\mathbf{1 4 4 . 8 4}$ & $\mathbf{1 2 7 . 2 3}$ & $\mathbf{9 . 6 7}$ \\
\hline ttest & & $1.7724^{*}$ & $17.9419^{* * *}$ \\
\hline
\end{tabular}

Note: statistical significance at $1 \%(* * *), 5 \%\left({ }^{* *}\right)$ and $10 \%\left({ }^{*}\right)$.

Moreover, our results are consistent with the theoretical previous work that used two sets of assumptions to guarantee the existence of Nash equilibria in the location and price games. On the one hand, it is consistent with the results found in Osborne and Pitchik (1987) using a mixed strategies approach; on the other, it is also a feasible outcome considering pure strategies with heterogeneous consumers as in Anderson et al. (1992).

Results using Euclidean distance in space and through the road network (shortest path) are only conclusive when the independent competitive firms setting is compared with the monopoly setting. This, as equality of means between regulated price and independent firms setting cannot be rejected. In Table iv are presented the distances between competitors for the different market definitions and the corresponding equality of means test. In the case of the independent competitive firms setting compared with the monopoly setting, results confirm that competition increases the spatial differentiation between firms.

Table iv: Distance among competitors measured in Euclidean and shortest path distances

\begin{tabular}{|l|r|r|r|r|r|r|}
\hline Distance & \multicolumn{3}{|c|}{ In space -Euclidean- } & \multicolumn{3}{|c|}{ In the network -shortest path- } \\
\hline Miles & half & one & two & half & one & two \\
\hline \hline Regulated price & 479.3 & 938.8 & 1787.9 & 480.86 & 910.2 & 1822.69 \\
\hline Independent firms & 457.8 & 902.9 & 1748.5 & 461.0 & 872.9 & 1776.5 \\
\hline ttest & -0.63 & -0.77 & -0.85 & -0.51 & -0.6885 & -0.748 \\
\hline \hline Monopoly & 361.8 & 720.6 & 1052.5 & 373.4 & 702.4 & 1088.2 \\
\hline Independent firms & 457.8 & 902.9 & 1748.5 & 461.0 & 872.9 & 1776.5 \\
\hline ttest & $3.2860^{* * *}$ & $4.2485^{* * *}$ & $12.0020^{* * *}$ & $2.6819^{* * *}$ & $3.7259^{* * *}$ & $10.7340^{* * *}$ \\
\hline
\end{tabular}

Note: statistical significance at $1 \%(* * *), 5 \%\left({ }^{* *}\right)$ and $10 \%(*)$.

Comparison between the locations chosen by independent single facility competitors and the ones that would have been chosen by a monopoly setting up the same number of facilities is shown in (Figure 3). 


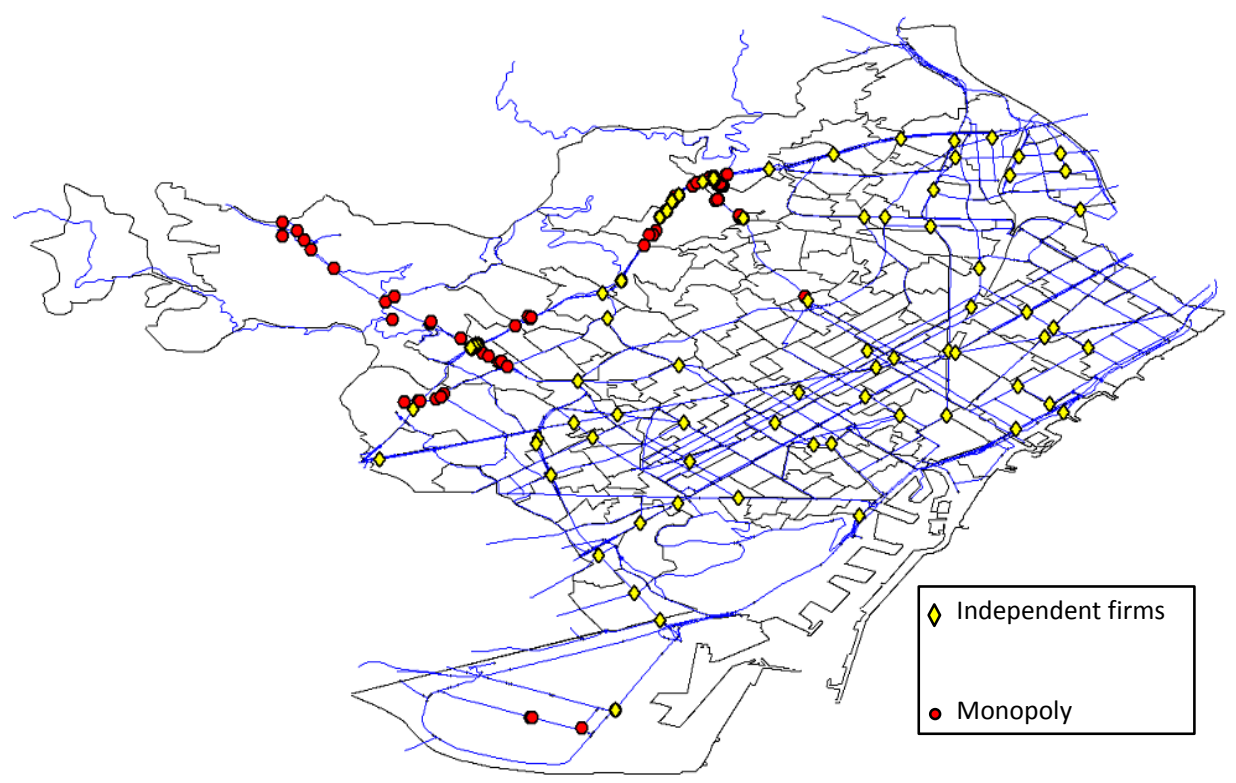

Figure 3: Locations equilibria at 5\% penetration rate: monopoly vs. independent competitors

As an additional interesting result looking at figure 3, the model shows that in a free pricing setting of independent single facility firms in competition, no zones in the city remain with a lack of supply of fast charging stations.

\section{E.3 The social welfare}

In this section we compute consumer and producer surplus, and also total welfare, to analyze whether some public intervention or a monopolic structure could render an improvement in social welfare with respect to the free price and location competition scenario.

As usual, we estimated welfare as the sum of the expected producer and expected consumer surpluses:

$$
S W=\sum_{j=1}^{J} E\left(\pi_{j}\right)+\sum_{i=1}^{I} E\left(C S_{i}\right)
$$

Following Train (2009) we calculated the expected consumer surplus in euros as:

$$
E\left(C S_{i}\right)=\frac{Y_{i}}{\alpha_{i} p_{j}} E\left[\max _{j}\left(\phi_{i j}+\varepsilon_{i j}\right)\right]
$$

where $\frac{\alpha_{i} p_{j}}{Y_{i}}$ is the marginal utility of income and $\max _{j}\left(\phi_{i j}+\varepsilon_{i j}\right)$ the alternative that provides the greatest utility to consumer i. The results presented are from simulating 100 times $\varepsilon_{i j}$ following a type-one extreme value distribution. 
We first compute social welfare to compare whether if a price regulation could improve the outcomes obtained under the free pricing and entry scenario. Results for the $3 \%$ and $5 \%$ of penetration of the electric vehicle are presented in (Table vii). As expected, in the free pricing scenario utility increases with the number of entrants as consumers value variety. Expected profits increase primarily because of the expansion of the market, while the business stealing effect is shown to exist, albeit only at a very low level. Total welfare therefore increases with the share of penetration of EVs.

The counterfactual given by the uniform regulated price show that in the $3 \%$ scenario, social welfare is higher with uniform prices that are set lower than the mean nonuniform unregulated prices, while in the $5 \%$ scenario the opposite outcome is obtained, welfare decreases with uniform prices that are set higher than the mean free prices. Hence, this implies that a policy intervention that sets a uniform price lower than the one obtained in the free pricing equilibrium while keeping the same number of facilities and the degree of differentiation may improve social welfare.

Moreover, in the $5 \%$ scenario, the higher welfare obtained in the free scenario is consistent with the results obtained in the spatial analysis (See Osborne and Pitchik 1987). By differentiating, firms tend to locate closer to the efficient result. Higher uniform pricing leads to clustering and to a less efficient equilibrium.

Further research should be aimed at assessing the extent to which different combinations of price regulations and/or transfers would provide better outcomes than those obtained with free entry, free pricing and no transfer equilibria. This question remains out from the scope of this paper.

Table v: Welfare decomposition and evolution. Free vs Regulated Pricing

\begin{tabular}{|l|rr|rr|}
\hline Share EV & \multicolumn{2}{|c|}{$\mathbf{3 \%}$} & \multicolumn{2}{c|}{$\mathbf{5 \%}$} \\
Setting & Free & Regulated & Free & Regulated \\
\hline Price $(€)$ & 18.87 & 16 & 18.55 & 26 \\
\hline Number of entrants & 51 & 51 & 83 & 83 \\
\hline Utility $(€)$ & $2,023,273,821$ & $3,573,555,810$ & $3,519,014,534$ & $2,552,805,932$ \\
\hline Standard deviation & $69,347,928.29$ & $80,165,929$ & $124,869,843$ & $127,680,934$ \\
\hline Expected Profits $(€)$ & 784,253 & 587,677 & $1,679,874$ & $2,238,592$ \\
\hline Total Welfare $(€)$ & $\mathbf{2 , 0 2 4 , 0 5 8 , 0 7 4}$ & $\mathbf{3 , 6 5 4 , 3 0 9 , 4 1 6}$ & $\mathbf{3 , 5 2 0 , 6 9 4 , 4 0 8}$ & $\mathbf{2 , 5 5 5 , 0 4 4 , 5 2 4}$ \\
\hline
\end{tabular}

Following, we use the $3 \%$ setting to compare the free entry case with situations where the location is regulated. Particularly, we estimate the social welfare of: i) randomly assign the same number of entrants; ii) assign the number of entrants to one zone of the city; iii) locate one entrant in every gasoline station.

Results are presented in Table vi by total welfare descending order. As observed, the free market allocation overcome any of the other scenarios in terms of consumer surplus, expected profits and total welfare.

With respect to utility, in the free setting scenario is more than five times bigger than the utility expected to be obtained in the other settings with the same number of entrants. Even in the case of the gasoline stations location, with 74 entrants, the utility of consumers is lower than in the free setting scenario. This work as expected, as these new locations do not take into account consumers mobility patterns nor amenities preference.

Expected profits are also lower in the regulated locations settings, arising to be negative 
in the one zone location. Again results worked as expected as the location of the facilities did not take into account nor costs nor expected sales at the locations.

Hence, we couldn't find any evidence supporting location regulation without taking into account demand and supply drivers. Finding whether it exist or not one location that improve total welfare following either utility or profits maximization is out of the scope of this article.

Table vi: Welfare decomposition. Free setting vs regulated location. 3\% scenario

\begin{tabular}{|c|c|c|c|c|}
\hline Setting & Free & Gasoline stations & Random & One zone \\
\hline Number of entrants & 51 & 74 & 51 & 51 \\
\hline Utility $(€)$ & $2,023,273,821$ & $1,969,488,880$ & $405,074,016$ & $389,989,752$ \\
\hline Standard deviation & $69,347,928$ & $76,218,851$ & $62,779,184$ & $37,122,942$ \\
\hline Expected Profits (€) & 784,253 & $553,340.37$ & 56,495 & $-98,981$ \\
\hline Total Welfare $(€)$ & $2,024,058,074$ & $1,970,042,221$ & $405,130,512$ & $389,890,770$ \\
\hline
\end{tabular}

Finally, we use the $5 \%$ setting analysis to compare the welfare obtained in the free entry of independent firms scenario with the monopoly situation. Our result is compatible with economic theory: the monopoly appropriates part of the consumer surplus and profits are higher but there is a loss in efficiency that implies a lower total welfare in the monopoly case.

Table vii: Welfare decomposition. Independent competitors vs Monopoly

\begin{tabular}{|l|r|r|}
\hline Setting & Independent firms & Monopoly \\
\hline Number of entrants & 83 & 361 \\
\hline Utility $(€)$ & $3,519,014,534$ & $1,339,784,013$ \\
\hline Standard deviation & $69,347,928$ & $180,872,477$ \\
\hline Expected Profits $(€)$ & 784,253 & $86,481,175$ \\
\hline Total Welfare $(€)$ & $\mathbf{3 , 5 2 0 , 6 9 4 , 4 0 8}$ & $\mathbf{1 , 4 2 6 , 2 6 5 , 1 8 8}$ \\
\hline
\end{tabular}

\section{E.4 Robustness checks}

We conducted several robustness checks for the results. Particulary, we tested the sensibility of results regarding the parameters and the sample. We also compare our results with the 5 European cities with the higher electric vehicle penetration rate and with the actual situation in Barcelona.

As for the consistency of the demand parameters, all robustness checks conducted support the reliability of the results obtained. First, we calculated the travel costs in line with Houde (2012): taking the rent ( $\mathrm{Y}$ ) to rent per minutes and in cents of euros, where the travel cost is given by $\frac{\lambda}{\bar{\alpha}+\alpha * \log (Y)}$. The results show the need for a 1.7119 cents difference in price in order to deviate one minute from the commuting path. Therefore, given an average recharge of $16 \mathrm{kWh}$, this implies a compensated cost for deviating to complete an average recharging of 16.43 euros per hour. This amount is similar to the average income of 13.07 euros per hour published by the statistics office IDESCAT for Catalonia for the year 2006 .

Second, the price elasticity of recharging at location $j$ with respect to the other locations and the outside good was obtained: the $3 \%$ scenario gives an average result of a 2.21 per cent reduction in quantity sold at location $\mathrm{j}$ for $j=1, \ldots, J$ because of a one per cent price increment; the $5 \%$ scenario gives a result of -2.23 . Of these amounts, a certain percentage is dedicated to the other locations and another to recharging at home. 
The price elasticity of recharging on the go with respect to recharging at home was also calculated. The results show how recharging at home increases with a one per cent increment in the price of the fast recharge. The outcome for the $3 \%$ scenario is -0.098 while that for the $5 \%$ scenario is -0.104 . Previous evidence for the demand elasticity of gasoline supports the calibration of the parameters used in this model. Espey (1998) meta-analysis includes studies published between 1966 and 1997 and he reports that estimates for the short-run price elasticity of gasoline ranged between 0 and -1.36 . Brons et al. (2008) meta-analysis draws on data published between 1978 and 1999 and the authors report estimates of price elasticity ranging between -1.36 and 0.37 , with the highest frequency of estimates in the -0.1 to -0.2 interval followed by the interval corresponding to estimators between 0 and -0.1 .

We also tested the sensibility of results regarding consumers price sensitivity and amenities preference. We first used the $3 \%$ electric vehicle penetration scenario to run the model increasing and decreasing price sensitivity. This is, changing the parameters $\alpha$ and $\alpha_{i}$. Results are presented in Table viii, where $\alpha=0.6$ and $\alpha_{i}=0.055$ correspond to the parameters used in the setting. As observed, results show a low sensitivity to price parameters changes and all main results hold for every specification. A change of a $30 \%$ in price sensitivity (the extreme cases) increases/reduces the number of entrants in 2, while the recharges on the go are of about an $8 \%$ for every specification. Additionally, the results show that, as expected, mean price increase when the consumers are less sensitive and decrease in the opposite case.

Table viii: Consumers price sensitivity robustness checks

\begin{tabular}{|l|l|l|l|l|l|}
\hline Setting & $\begin{array}{l}\alpha=0.45, \\
\alpha_{i}=0.04\end{array}$ & $\begin{array}{l}\alpha=0.6, \\
\alpha_{i}=0.055\end{array}$ & $\begin{array}{l}\alpha=0.65, \\
\alpha_{i}=0.06\end{array}$ & $\begin{array}{l}\alpha=0.7, \\
\alpha_{i}=0.065\end{array}$ & $\begin{array}{l}\alpha=0.85, \\
\alpha_{i}=0.08\end{array}$ \\
\hline Number of entrants & 53 & 52 & 51 & 51 & 49 \\
\hline Share 'on the go' & 8.12 & 8.14 & 8.06 & 8.09 & 7.92 \\
\hline Mean price $(€)$ & 20.41 & 19.2 & 18.87 & 18.51 & 17.61 \\
\hline
\end{tabular}

Notes $\alpha=0.6$ and $\alpha_{i}=0.055$ are the parameters used in the model.

Second, we used the same share of EV to test the sensibility of results respect to amenities preference. Results show that when preference for amenities increase in around a $10 \%$ the number of entrants increase in one, while when the preference decreases by the same quantity entrants remain in 51.

Respect to the sample, we generated six additional random samples following the same procedure than in the original one to test the sensibility of results regarding the sample selection. After running the model for the three electric vehicle rates of penetration for each sample, we constructed the confidence intervals of the mean of the distribution to test whether our original sample results hold inside. For a $99 \%$ confidence interval, the original sample renders a result in the number of stations that are inside the confidence interval ${ }^{4}$. This also holds for the $1 \%$ and $3 \%$ electric vehicle rates for a $95 \%$ confidence and $90 \%$.

Additionally, we tested how results would change if the adoption wasn't random but similar to the groups that have already adopted the electric vehicle in other countries. This is, we selected a random sample within the young population (until 44 years old) and with the highest income. As showed in Table ix, main results hold: a market proves to be self-sufficient

\footnotetext{
${ }^{4}$ Confidence intervals are [ $\left.-0.693 .55\right]$, [40.82 54.52] and [44.79 84.71], respectively for the $1 \%, 3 \%$ and $5 \%$ share of EV.
} 
from a $3 \%$ electric vehicle penetration rate, the number of entrants increase with the electric vehicle share and price decreases with the number of entrants.

Table ix: Random vs young and with high income samples

\begin{tabular}{|l|r|r|r|r|r|r|}
\hline Share EV & \multicolumn{2}{|c|}{$\mathbf{1 \%}$} & \multicolumn{2}{|c|}{$\mathbf{3 \%}$} & \multicolumn{2}{|c|}{$\mathbf{5 \%}$} \\
\hline Setting & Random & Young & Random & Young & Random & Young \\
\hline Number of entrants & 2 & 2 & 51 & 58 & 83 & 71 \\
\hline Share 'on the go' $(\%)$ & 0.482 & 0.53 & 8.06 & 8.49 & 8.35 & 9.47 \\
\hline Mean price (€) & 25.09 & 20.78 & 18.87 & 18.64 & 18.55 & 18.52 \\
\hline
\end{tabular}

Finally, we compare our results with the five European cities with the higher electric vehicle penetration rate and with the actual situation in Barcelona. Table below presents the rate of penetration at country level, and the number of fast charging stations in the different cities. For the case of Barcelona, with a $0.2 \%$ of penetration rate, our model predicts less than two fast charging stations. This is compatible with the current situation as although in the table appear 25 stations, only one of them is private. The rest were located by the local government without any mobility or business criteria. Moreover, as our model predicts, the unique private station is located in a gasoline station with car wash and amenities (supermarket, bar,...). In general, table shows a positive relationship between the share of the electric vehicles and the number of fast charging stations. However, the relationship seems not to be linear so exists other drivers that affect the entry of stations like density of population, mobility patterns and costs. Therefore, like in our model, is important take into account all these factors and not only the penetration rate.

Table x: EV and fast charging stations in Europe

\begin{tabular}{|l|l|l|l|}
\hline Country & $\begin{array}{l}\text { Stock of EV } \\
\text { and } \\
(\mathbf{\%}) *\end{array}$ & $\begin{array}{l}\text { No. of sta- } \\
\text { tions** }\end{array}$ & $\begin{array}{l}\text { Density of pop- } \\
\text { ulation*** }\end{array}$ \\
\hline Norway (Oslo) & 12.5 & 34 & 1,400 \\
\hline Netherlands (Amsterdam) & 3.9 & 26 & 4,908 \\
\hline Sweden (Stockholm) & 1.4 & 29 & 4,800 \\
\hline Denmark (Copenhagen) & 0.9 & 24 & 7,400 \\
\hline France (Paris) & 0.7 & 36 & 21,258 \\
\hline Spain (Barcelona) & 0.2 & $25 \dagger$ & 15,687 \\
\hline
\end{tabular}

Notes * International Energy Agency (2014), Plug-in Hybrid Electric Vehicle (PHEV); *

Chargemap.com. Number of fast charging stations in a radius of $25 \mathrm{~km}$ around the city center; $^{* * *}$ Eurostat; $\nmid$ From the 25 , only 1 is private.

\section{F Concluding remarks}

This paper has simulated a full game of strategic interaction to model the entry and location of fast charging stations for electric vehicles. It draws on mobility information in the city of Barcelona for both residents and commuters together with their income and demographic data. Additionally, it employs information about the road network, petrol stations and other amenities, including super/hypermarkets, and the cost of location around the city to simulate 
the equilibria of the game. Robustness checks conducted on the parameters support the evidence provided by the simulation.

A sufficient network of fast charging stations is only found to offer a solution for 'range anxiety' when the electric vehicle penetration rate rises above $3 \%$. For the $3 \%$ and $5 \%$ scenarios, a unique stable equilibrium is achieved with the entry of 51 and 83 firms, respectively. Thus, our results indicate that a system of transfers to support a network of fast charging stations is not needed if electric vehicles attain a significant rate of market penetration. However, this threshold is 15 times higher than the current penetration rate in Barcelona.

Demand drivers seem to have a stronger influence than entry costs in determining the localization of the fast charging stations. Further, when competing in terms of location and price, firms seem to differentiate from competitors more in spatial terms than when they are in the same setting with a uniform price or in comparison to the monopoly case. 'Market power effect' and 'market expansion effect' seem to be stronger than the 'business stealing effect'The model also shows that without any entry restrictions the entire geographical space would be supplied with fast charging stations.

As it is usual in differentiated product markets, consumers show a preference for variety. Here, the market expands with the rise in penetration of electric vehicles in two ways: first, in response to the growth in the need for electricity and, second, because of the greater demand for recharging on the go.

The counterfactual establishing uniform regulated prices shows that a policy intervention in the form of a uniform price lower than that obtained in the free-pricing equilibrium would improve social welfare. However, policy intervention is not found to improve welfare for every level of penetration of electric vehicles.

Further research will be conducted to assess the extent to which different combinations of transfers and price regulations would provide better outcomes than those obtained with free entry, free pricing and no transfer equilibria.

\section{References}

Ahman, M. (2001). Primary energy efficiency of alternative powertrains in vehicles. Energy, 26, 973-989.

Anderson, S., A. de Palma, and J.-F. Thisse (1992). Discrete Choice Theory of Product Differentiation. The MIT Press,.

Bajari, P. H. H. J. K. and D. Nekipelov (2010). Estimating static games of strategic interaction. Journal of Business \& Economics Statistics, 28 (4), 469-89.

Berry, S., J. Levinsohn, and A. Pakes (1995). Automobile prices in market equilibrium. Econometrica, 63 (4), 841-90.

Borenstein, S. and J. Netz (1999). Why do all the fights leave at 8 a.m.? competition and departure-time differentiation in airline markets. International Journal of Industrial Organization, 17, 611-40.

Borrell, J. and L. Fernandez-Villadangos (2011). Clustering or scattering:the reasons underlying distance regulations between retail outlets. Preliminary draft, Research Group on Governments and Markets (GiM)- Dep. De Poltica Econmica, Institut d'Economia Aplicada (IREA), Universitat de Barcelona.

Borrell, J.-R. and C. Casso (2011). Welfare and geographic entry policies. 
Brons, M., P. Nijkamp, E. Pels, and P. Rietveld (2008). A meta-analysis of the price elasticity of gasoline demand. a sur approach. Energy Economics, 30, 2105-22.

Buenstorf, G. and S. Klepper (2010). Why does entry cluster geographically? Evidence from the US tire industry. Journal of Urban Economics, 68, 103-14.

D'Aspremont, C., J. J. G. and J. R. Thisse (1979). Hotelling's stability in competition. Econometrica, 47, 1145-50.

Dijkstra, E. W. (1959). A note on two problems in connexion with graphs. Numerische Mathematik, 1 (1), 269-271.

Elizalde, J. (2013). Competition in multiple characteristics: An empirical test of location equilibrium. Regional Science and Urban Economics, 43, 938-50.

Espey, M. (1998). Gasoline demand revisited: an international meta-analysis of elasticities. Energy Economics, 20, 273-95.

Helveston, J., Y. Liu, E. McDonnell Feit, E. Fuchs, E. Klampfl, and J. J. Michalek (2015). Will subsidies drive electric vehicle adoption? measuring consumer preferences in the u.s. and china. Transportation Research Part A, 73, 96-112.

Hengl, T. (2009). A practical guide to geostatistical mapping, 2 edn,. Office for Official Publications of the European Communities.

Hotelling, H. (1929). Stability in competition. Economic Journal, 39, 41-57.

Houde, J.-F. (2012). Spatial differentiation and vertical mergers in retail markets for gasoline. American Economic Review, 5, 2147-82.

Jenn, A., I. Azevedo, and P. Ferreira (2013). The impact of federal incentives on the adoption of hybrid electric vehicles in the united states. Energy Economics, 40, 936942.

Larson, P., J. Vifara, R. V. Parsons, and A. Elias (2014). Consumer attitudes about electric cars: Pricing analysis and policy implications. Transportation Research Part A, 69, 299314.

Netz, J. and B. A. Taylor (2002). Maximum or minimum differentiation? location patterns of retail outlets. The Review of Economics and Statistics, 84(1), 162-75.

Osborne, M. J. and C. Pitchik (1987). Equilibrium in hotelling's model of spatial competition. Econometrica, 55 (4), 911-22.

Parsons, G., M. Hidrue, W. Kempton, and M. Gardner (2014). Willingness to pay for vehicle-to-grid (v2g) electric vehicles and their contract terms. Energy Economics, 42, 313-324.

Pennerstorfer, D. and C. Weiss (2013). Spatial clustering and market power: Evidence from the retail gasoline market. Regional Science and Urban Economics, 43, 661-75.

Pinske, J. and M. Slade (1998). Contracting in space. Journal of Econometrics, 85(1), $125-54$.

Salvanes, K., F. Steen, and L. Sorgard (2005). Hotelling in the air? flight departures in norway. Regional Science and Urban Economics, 35, 193-213.

Schroeder, A. and T. Traber (2012). The economics of fast charging infrastructure for electric vehicles. Energy Policy, 43, 136-144. 
Seim, K. (2006). An empirical model of firm entry with endogenous product type choices. RAND Journal of Economics, 37 (3), 619-640.

Train, K. E. (2009). Discrete Choice Methods with Simulation. Cambridge University Press,.

Vitorino, M. A. (2012). Empirical entry games with complementarities: An application to the shopping center industry. Journal of Marketing Research, 49(2), 175-91.

WWF (2008). Plugged in: The end of oil age. Technical report, World Wide Fund for Nature (WWF). 


\section{Appendix A Kriging and Origin Destination Matrix}

Kriging is an interpolation method used to predict the unknown values of a variable given the spatial correlation presented by the observable values. The technique uses both the distance and the degree of variation between known data points to estimate values in unknown areas. The degree of relation between points is measured by using the semivariance. As the distance between points to be compared increases so does the semivariance.

\section{A.1 Ordinary Kriging fundamentals}

As presented in Hengl (2009) ordinary kriging is based on the model presented below. For expository reasons, the variable that is spatially distributed along $\mathrm{x}$ (latitude and longitude) locations will be called o, the known values of the variable will be presented as $o\left(x^{c}\right)$ and at unobserved locations as $o\left(x^{e}\right)$.

$$
o(x)=\mu(x)+\varepsilon(x)
$$

where $\mu(x)$ is the global mean and $\varepsilon(x)$ the spatially correlated stochastic part of the variable $o$. By using ordinary kriging the predictions of the value of a variable at some new location $x^{e}$ are given by:

$$
\widehat{o}\left(x^{e}\right)=\sum_{e=1}^{N} w_{e}\left(x^{e}\right) o\left(x^{c}\right)
$$

where $w_{e}$ are the kriging weights and $o\left(x^{c}\right)$ the values at the observed locations.

This is the same as:

$$
\widehat{o}\left(x^{e}\right)=\lambda_{e} o^{c}
$$

with $\lambda_{e}$ the vector of kriging weights and $o^{c}$ the vector of $C$ observed values.

The technique uses the semivariance $\gamma(h)$ to express the degree of relationship between points (weights):

$$
\gamma(h)=\frac{1}{2} E\left[o\left(x^{c}\right)-o\left(x^{c}+h\right)^{2}\right]
$$

where $o\left(x^{c}\right)$ is the value of the variable at some observable location and $o\left(x^{c}+h\right)$ the value of the neighbour at a distance $x^{c}+h$. By plotting all semivariances versus the separation distances a variogram is obtained. And using the average values for a standard distance called 'lag' an experimental variogram is obtained. As expected, semivariances should be smaller at shorter distance and at certain distance 'sill' should stabilize.

After obtaining the experimental variogram this is fitted to some theoretical variogram model such as the linear, spherical, gaussian, exponential, etc

\section{A.2 Kriging Results}

The estimation was made twice, once for origins and again for destinations. In our case the known values are, as stated, $63\left(o^{b}=1,2, \ldots, 63\right)$ and the unknowns $828\left(o^{e}=1,2, \ldots, 828\right)$. For destinations, the variable could be renamed with the same amount of known and unknown values.

In both cases, the experimental variogram was fitted to a theoretical model using a least squares fit of various theoretical variograms to an experimental, isotropic variogram. 
The theoretical model was chosen using the goodness of fit criterion as several models were tested (spherical, pentaspherical, exponential, gaussian, circular, mattern, among others). The theoretical model selected for both origin and destination variables was the linear model.

In the case of origins, the Gaussian model presented a higher goodness of fit than that of the linear model, but some results for the unobserved positions became negative because of the nonlinearity of the weights. As the difference in goodness of fit was almost imperceptible between models ( 0.7111 over 0.7093$)$, we decided to use the Linear for both samples. The goodness of fit for origins is 0.7093 and for destinations 0.7208 . The variograms are presented in Figure A.2.1, a and b.

\section{Figure a. Origins}

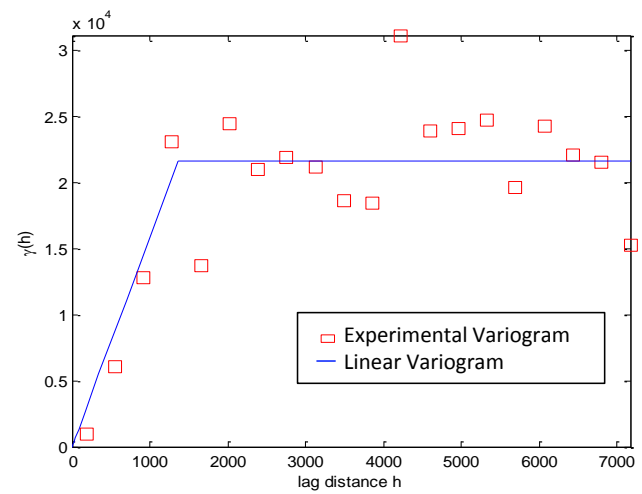

Figure b. Destinations

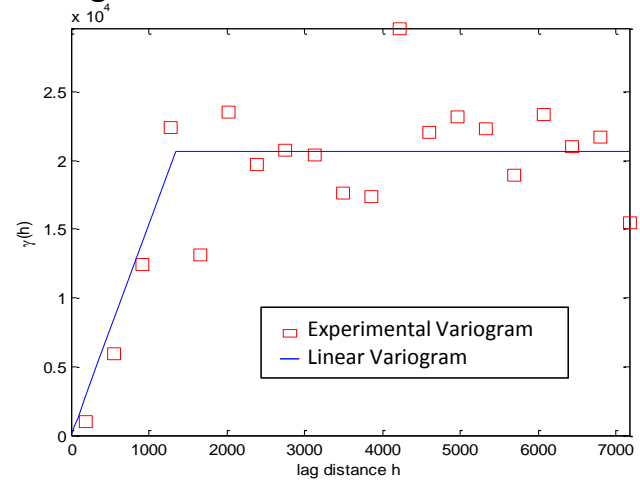

Figure A.2.1: Experimental and Theoretical Variograms

\section{A.3 Construction of the OD Matrix within Barcelona}

As stated, the kriging technique was applied to distribute origins and destinations within Barcelona across the whole road network. By making use of the number of trips at observed locations (node centroids) and the spatial correlation between observed values, we were able to approximate the number of trips at unknown locations (rest of nodes in the network). Additionally, we used the distribution of population within the city to establish the weight of each node and to distribute existing trips across the full network. 
We ran the procedure described below twice: first for origins, with the variable value being the number of trips originating from node $\mathrm{x}, o(x)$; and, second for destinations, with variable value being the number of trips with their destination at node $\mathrm{x}, d(x)$. For expositive reasons we explain the procedure using only $o$.

Data used: 1. number of trips at each origin and destination;2. georeferences; 3 . population of every neighbourhood of Barcelona;4. population at census areas within the city.

Steps: 1st step. We distributed the population of Barcelona between the 63 original origin- destination nodes $\left(o^{b} a n d d^{b}\right)$. This was achieved by assigning the population of the neighborhoods of Barcelona to the corresponding node (centroid of the survey zone). For the case of neighborhoods without a centroid, the population was assigned using the distance criterion to the closest node. Henceforth, population at each known location is referred to as $P\left(x^{c}\right)$.

2nd step. We obtained our weighted observed values $\left(w o\left(x^{c}\right)\right)$ by dividing the number of trips at every observed location $o\left(x^{c}\right)$ by the corresponding population at the location $P\left(x^{c}\right)$ :

$$
w o\left(x^{c}\right)=\frac{o\left(x^{c}\right)}{P\left(x^{c}\right)}
$$

for every $c=1,2, \ldots, 63$

3rd step. We applied the ordinary kriging method. This involved the construction of the experimental variogram; the fitting of the latter to the authorized variogram; and, the interpolation of the values using kriging. From this step we obtained the $\widehat{w o}\left(x^{e}\right)$ for every $i=1,2, \ldots, 828$ unknown values. Combining known and unknown values we have a total of 891. Total estimators are $w o(x)$, where $x=1,2, \ldots, 891$

4th step. We distributed the population of Barcelona across all the nodes of the network (891) by using the map of census areas. Population at node $x$ can be expressed as $P(x)$.

5 th step. We obtained the new number of trips at each location $\widehat{o}(x)$ by multiplying the $\widehat{w o}(x)$ by the population obtained in $4 P(x)$ :

$$
\widehat{o}(x)=o(x) P(x)
$$

with, as stated, $P(x)$ the population by node assigned in step 4 and $(x=1,2, \ldots, 891)$

6th step. By using the estimators obtained in $5(\widehat{o}(x))$ we were able to create a probability of being chosen for every node in the network.

\section{Appendix B Sample Selection}

We need to integrate by simulation $\grave{a}$ la BLP over a set of individuals that have idiosyncratic tastes. We take a 100 draws from a sample of 18411 trips for which we know origin, destination and personal characteristics. The selection was made taking into account the number of trips of the population that each in the survey represents.

\section{B.1 The weights}

Every trip of the survey has assigned a survey weight according to the trips made by the entire population of the region. This survey weight was assigned by the Metropolitan Agency 
of Transport considering the mobility characteristics of the trip and socioeconomic characteristics of the people surveyed. From now on, we will express the trip made in between origin and destination $(\mathrm{o}, \mathrm{d})$ as $l$ and survey weight as $s w_{i l}$. This last expression accounts for all the trips $l$ made by the population with equal characteristics.

\section{B.2 The Selection}

Each journey made by private transport containing at least origin or destination in Barcelona constitutes our full survey. The sample was randomly selected taking into account the sample weight generated as described in the equation below:

$$
\varpi_{i l}=\frac{s w_{i l}}{\Sigma_{l=1}^{L} s w_{i l}}
$$

with, $\varpi_{i l}$ the sample weight, $s w_{i l}$ the survey weight, and $L=18411$. 